\title{
Bivalves (Tellinacea: Donacidae) on a North Carolina Beach: Contrasting Population Size Structures and Tidal Migrations
}

\author{
Kenneth M. Leber* \\ Department of Biology, East Carolina University, Greenville, North Carolina 27834, USA
}

\begin{abstract}
Populations of the beach clams Donax parvula and Donax variabilis overlap spatially in North Carolina (USA). However, previous studies may have lumped these species. Hence differential patterns of growth and potential differences in tidal migrations may have been obscured. Intertidal populations of Donax spp. were sampled monthly during 1976 and 1977 with a core tube and a hand dredge along transects perpendicular to shore. Juveniles of 2 Donax species colonized the beach in late winter. $D$. variabilis individuals grew more rapidly than $D$. parvula, and these 2 populations were easily distinguished during summer by size differences. Tidal migrations of both species ceased in late summer. $D$. parvula moved offshore, but $D$. variabilis remained on the beach, stranded during low tides. These populations appear to undergo seasonal migrations between beach and subtidal habitats. Emigrations from the beach may be related to temperature declines and reproductive requirements. Summer stranding of $D$. variabilis might be an adaptation to fish and crab predation, or an avoidance reaction to crowding stress.
\end{abstract}

\section{INTRODUCTION}

Bivalves of the genus Donax, which frequent sandy beach intertidal zones, often rank high among dominant beach macrofauna components along the western Atlantic coast (Pearse et al., 1942; Edgren, 1959; Wade, 1967; Leber, 1977; Matta, 1977; Reilly and Bellis, 1978). Although population studies have been reported for many western Atlantic Donax species (Morrison, 1971), others have been neglected, especially Donax parvula Philippi, which frequents southeast USA beaches.

Whereas Donax parvula is easily distinguished from $D$. variabilis Say by the lack of distinct radial sculpture over most of the shell, it has often been misidentified as $D$. variabilis. Some studies of North Carolina Donax south of Cape Hatteras (Pearse et al., 1942; Turner and Belding, 1957; Dexter, 1969) have not distinguished between $D$. variabilis and the smaller D. parvula (Morrison, 1971; Hugh Porter, pers. comm). Thus, possible differences in growth or tidal migrations may have been obscured. Seasonal changes in population size

\footnotetext{
- Present address: Department of Biological Science, Florida State University, Tallahassee, Florida 32306, USA
}

structure and tidal migrations are described here for $D$. variabilis and $D$. parvula from a North Carolina high-wave-energy beach.

\section{MATERIALS AND METHODS}

Donax spp. were sampled monthly from January 1976 through April 1977 during a 15 month comparison of beach macrofauna (Leber, 1977) at Bogue Banks, a North Carolina barrier island (Fig. 1). The study site is about $30 \mathrm{~km}$ West of Morehead City (Carteret Co., NC), $1.5 \mathrm{~km}$ East of Bogue Pier, and encompasses $1 \mathrm{~km}$ of shore on this south facing, high-energy beach. Waves at the study site were typically 0.5 to $1.3 \mathrm{~m}$ from crest to trough during the study. Width of the beach from the base of the fore dune to spring tide high water mark averaged $15 \mathrm{~m}$. Beach slope ratio averaged 11:1. The low tide terrace added an additional $40 \mathrm{~m}$ to beach width during low spring tides. Semidiurnal tidal fluctuations varied in amplitude from 0.7 to $1.25 \mathrm{~m}$. The beach was composed of quartz sand with a median grain size of $250 \mu \mathrm{m}$ (Leber, 1977). I discriminated 4 zones: spray, damp, wash and surf (Fig. 2) after Wade's (1967) scheme in which there was no damp zone. 


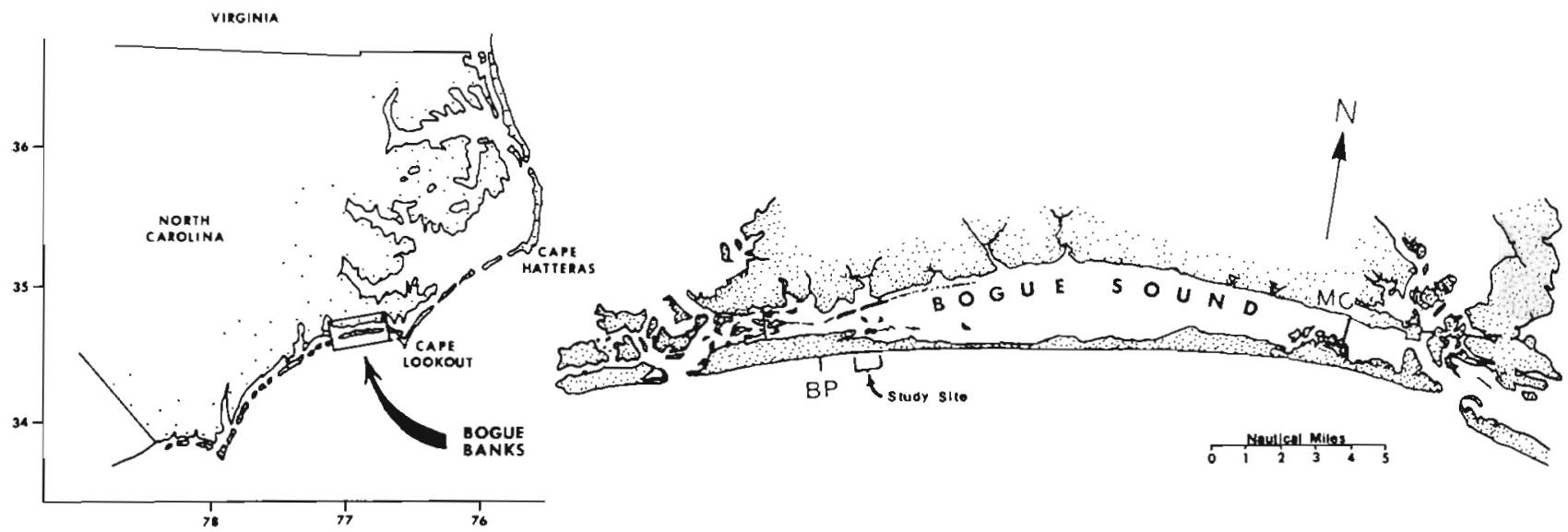

Fig. 1. Study site on Bogue Banks, North Carolina, USA. BP: Bogue Pier; MC: Morehead City

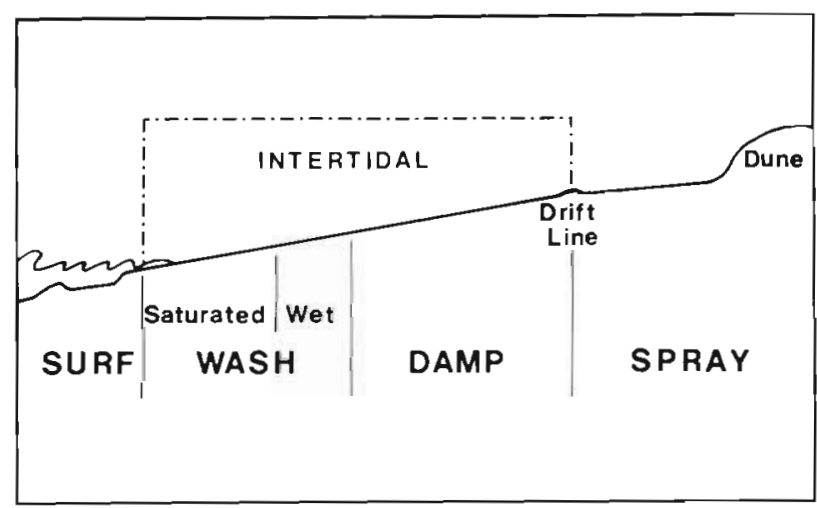

Fig. 2. Profile of study area indicating beach zonation during ebb tide (modified after Wade, 1967). Wash zone: covered intermittently by each incoming wave; its movement up and down the beach slope is governed by tidal flow. Damp zone: area of intertidal zone left exposed on ebbing tide; at its uppermost boundary lies the drift line that is deposited at high tide and consists of accumulated plant and animal debris

Monthly collections were made during mid to low tides along transects perpendicular to shore with $5 \mathrm{~cm}$ diameter cores, sieved through $1 \mathrm{~mm}$ mesh screen, and by a $1 \mathrm{~mm}$ mesh lined hand dredge that was pulled through the wash zone. Five replicate cores spaced $1 \mathrm{~m}$ apart, and perpendicular to the transect axis, were taken at $2 \mathrm{~m}$ intervals along a transect. Core sampling was supplemented by hand dredge sampling to collect large numbers of individuals for population size distribution analyses. Replicate dredge hauls were obtained from low, mid, and upper wash zone levels. Specimens were preserved in $70 \%$ ethanol and identified and measured (shell length) at the laboratory.

\section{RESULTS}

Juvenile recruitment to the wash zone occurred in 1976 during both February and November for Donax variabilis, and in February for D. parvula (Fig. 3).
Recruitment individuals of both species were partially missed by samples owing to the large mesh size of sieves. The smallest individuals fell through the $1 \mathrm{~mm}$ mesh; however, damped recruitment pulses are obvious in the size frequency histograms (Fig. 3). Secondyear $D$. variabilis recolonized the wash zone in March, presumably after overwintering in subtidal areas. $D$. variabilis exhibited rapid growth during early summer, and by July modal size of the population was

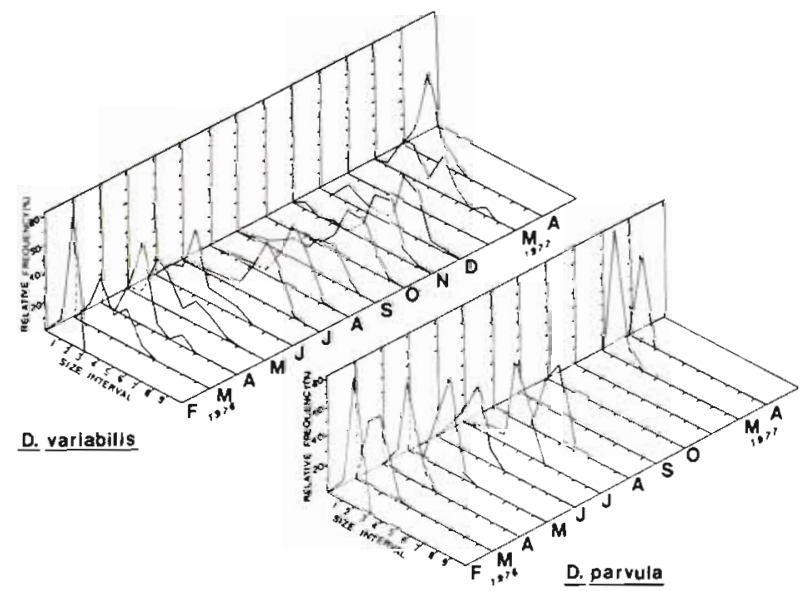

Fig. 3. Donax size-frequency diagrams for individuals collected during study. Shell length indicated in $2.5 \mathrm{~mm}$ intervals; first interval is $3.5-6.0 \mathrm{~mm}$. January 1976 and 1977 , and February 1977 are not included as fewer than 10 individuals were collected in those months

considerably larger than that for the $D$. parvula population (Fig. 3). Donax were most abundant during spring and summer; tidal migrations of both species varied seasonally (Leber, in press) and are summarized below.

Donax variabilis and $D$. parvula migrated together in the wash zone through July 1976, their position on the beach fixed by tidal patterns. But in August, $D$. parvula disappeared from intertidal zone samples. There was no indication of mortality, but rather, a seaward migra- 
tion of $D$. parvula from the wash zone on the beach to a subtidal habitat. $D$. parvula individuals were collected with cores in $1 \mathrm{~m}$ deep water in the surf zone following their disappearance. Tidal migrations of $D$. variabilis also ceased in August, however, the population remained high on the beach in damp sand, only briefly submerged during high tides (Fig. 4).

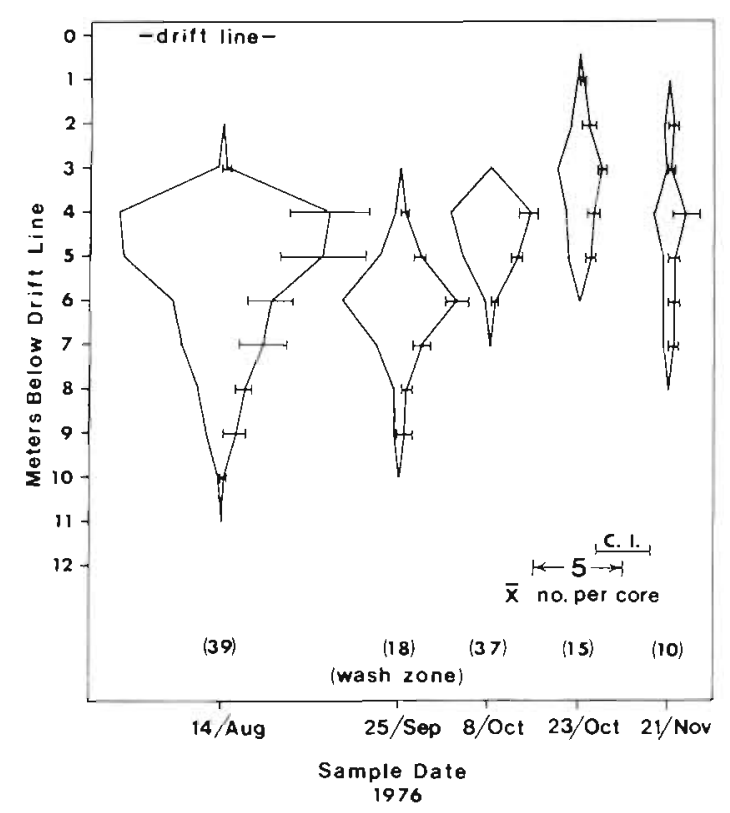

Fig. 4. Donax variabilis. Mean number per core and $95 \%$ confidence intervals for individuals stranded on beach during ebb tides in late summer and fall 1976. Individuals were not found stranded during other months, but migrated up and down the beach with the tide. Distances (m) of top of wash zone from drift line at start of collections is given in brackets. Confidence intervals are symmetrical, but indicated here only for right margins of kite diagrams

During low-tide collections in late summer and fall, the Donax variabilis population remained concentrated in a narrow ( 3 to $7 \mathrm{~m}$ ) band high in the intertidal zone (Fig. 4). By late November, densities had declined, and individuals were buried $10 \mathrm{~cm}$ deep in the sand. $D$. variabilis disappeared from collections in December, and few individuals $(<10)$ were found during January or February 1977 despite intensified sampling efforts. Juvenile $D$. parvula and $D$. variabilis recolonized the beach in March 1977.

Water temperatures during this study ranged from $5^{\circ}$ to $28^{\circ} \mathrm{C}$, air temperatures from $2^{\circ}$ to $38^{\circ} \mathrm{C}$ (Leber, in press). Fall temperatures were characterized by a steep decline.

\section{DISCUSSION}

Pearse et al. (1942) and Turner and Belding (1957) describe Donax variabilis as a daily tidal migrant that maintains its position in the wash zone throughout tidal cycles. Edgren (1959) and Marsh (1962) report stranding of this species at low tide. Both patterns were evident for $D$. variabilis at Bogue Banks until December when the clams disappeared from the intertidal zone. Stranding was not observed for D. parvula, which moved to a subtidal habitat in mid summer. Summer habitats of these 2 congeners parallel those reported for $D$. variabilis and $D$. texasianus Philippi in Texas by Loesch (1957), those for D. striatus Linné and $D$. denticulatus Linné in the West Indies by Wade (1967), and those for $D$. variabilis ( $D$. roemeri protracta) and $D$. fossor Say in North Carolina by Morrison (1971).

The disappearance of Donax variabilis from the beach in December was likely a consequence of emigration. Matta (1977) has noted D. variabilis movements into offshore regions in fall in North Carolina. The most parsimonius explanations for emigrations of Donax spp. from beach to subtidal habitats are that these movements are physically controlled, and/or a consequence of spawning requirements. The late fall exodus of $D$. variabilis from the beach coincided with a sharp decrease in water temperature from October $\left(27^{\circ} \mathrm{C}\right)$ to November $\left(13^{\circ} \mathrm{C}\right)$ (Leber, in press). Both $D$. parvula and $D$. variabilis appear to spawn during winter, as the beach was repopulated by juveniles in the spring. Thus, reproduction could be contingent upon temperature regulated emigration from the beach to a subtidal habitat.

Alternatively, the gradual decrease in Donax variabilis abundance may have been a consequence of predation by fish (Menidia menidia, Menticirrhus americanus, Paralichthys sp., Trachinotus carolinus) and crabs (Ocypode quadrata, Arenaeus cribrarius) that feed at night in the wash zone on Donax, and are abundant in late summer (Leber, in press). Also, lowtide stranding of $D$. variabilis high in the intertidal zone during late summer and fall may be an adaptation to predation pressure. A population remaining high on the beach throughout tidal exchanges would be exposed to these wash zone predators only at night during high tides.

Behavioral mechanisms involved in tidal migrations of Donax were discussed by Mori $(1938,1950)$, Turner and Belding (1957), Wade (1967), Ansell (1969), Trueman (1971), and McLachlan et al. (1979). When temporarily stranded in damp sand on a falling tide, reduced intensity of stimulation from acoustic wave shock and drying sand induce both $D$. denticulatus and $D$. variabilis to respond to the backwash of a wave by pushing upward with the foot and emerging from the substrate, whereupon they are carried down the beach by wave drag (Turner and Belding, 1957; Trueman, 1971). Emergence from the sand during flood tide is 
apparently related to both a behavioral response to some threshold level of acoustic shock, as waves pound closer to the clams, and erosion of sand by the churning motion of waves (Trueman, 1971). Clams are then transported up the beach after emergence by the momentum of advancing waves.

The basis for low-tide stranding of Donax variabilis, which clearly underwent tidal migrations for several months prior, is another matter. Stranding high in the intertidal is a consequence of interrupted tidal migration, owing to a lack of response to environmental cues that stimulate emergence on an ebb tide. This behavior reversal might be explained as a sequential step in a metabolic shutdown in order to avoid excessive energy use owing to some physical condition, or to low food availability. But what is the adaptive significance of becoming inactive in a hostile habitat, the upper intertidal, that is subjected to long periods of exposure? Rather, a stress-induced shutdown would likely occur in a more optimal location such as mean tide level, or closer to low tide level on the beach.

Alternatively, this behavior reversal, which initiates stranding of the entire population, might be an antipredatory adaptation. The origin of emergence behavior in several bivalves can be traced partly to a chemosensory response to certain predators (Ansell, 1969; Ansell and Trevallion, 1969). During the evolution of tidal migratory behavior, Donax variabilis movements up the beach on flood tides may have been reinforced by an escape response to crab and fish predators. Were predation on Donax intense, down slope migrations on the ebb tide would have been selected against. Selection would favor individuals that discontinued migrations. Following this hypothesis, stranding should be advantageous only during periods of high predation intensity. The environmental cue for stranding behavior in extant D. variabilis populations might be increased frequency of harrassment by predators. Any demonstration that stranding in $D$. variabilis is initiated during periods of low wash zone predation intensity (winter and spring months at Bogue Banks) would falsify this hypothesis.

Finally, late summer stranding of Donax variabilis, concurrent with the movement of $D$. parvula into subtidal regions, may have been a response to spatial limitations imposed by the vast numbers of mole crabs, Emerita talpoida Say, and Donax migrating together in the wash zone at that time. As combined Donax and Emerita densities in the wash zone approached 5,000 ind. $\mathrm{m}^{-2}$ in August (Leber, in press), filter feeding by Donax might have been impaired. During a later study at the same site (Reilly and Bellis, 1978), densities of Donax and Emerita were considerably lower, and any crowding effects correspondingly reduced. Neither stranding of $D$. variabilis, nor a summer exodus of D. parvula were evident in that study.

The present study shows that 2 Donax species present on Bogue Banks in 1976 and 1977 differed in population size structures and occupied vastly different summer habitats. Whereas $D$. parvula moved to deeper water in late summer, $D$. variabilis clearly remained aggregated during late summer and fall in a high-density narrow band located in the upper intertidal zone. The basis for low-tide stranding of $D$. variabilis is still far from clearly established, and hypotheses posed here that account for stranding need critical evaluation. Lab and field experiments are needed to assess any predation or crowding effects on Donax migrations.

Acknowledgements. This study, supported by East Carolina University's Institute for Coastal and Marine Resources, and the Department of Biology, was part of the work required for the Master of Science degree. I am grateful to Steve Blumenthal, Tim Charles, Myron Civils, Rick Honn, Duncan Keller, Debbie Landy, Chris Leber, and Frank Reilly for help in the field. I owe special thanks to Ed Ryan, my thesis advisor, for help and guidance during this study. Species identifications were confirmed by Hugh Porter of the UNC Marine Laboratory, Morehead City, N.C. I thank Bruce Felgenhauer, William Herrnkind, Kevan Main, Don Strong, and 3 anonymous reviewers for critical comments on this manuscript. Support during preparation of the manuscript was provided by the Department of Biological Science at Florida State University.

\section{LITERATURE CITED}

Ansell, A. D. (1969), Leaping movements in the bivalvia. Proc. malac. Soc. Lond. 38: 387-399

Ansell, A. D., Trevallion, A. (1969). Behavioural adaptations of intertidal molluscs from a tropical sandy beach. J. exp mar. Biol. Ecol. 4: 9-35

Dexter, D. M. (1969). Structure of an intertidal sandy-beach community in North Carolina. Chesapeake Sci. 10: 93-98

Edgren, R. A. (1959). Coquinas (Donax variabilis) on a Florida beach. Ecology 40: 498-502

Leber, K. M. (1977). Seasonal community dynamics of macrobenthos on a high energy sandy beach in North Carolina. M. S. thesis, East Carolina Univ., Greenville, North Carolina

Leber, K. M. (in press). Seasonality of macroinvertebrates on a temperate, high wave energy sandy beach. Bull. mar. Sci.

Loesch, H. C. (1957). Studies of the ecology of two species of Donax on Mustang Island, Texas. Publs Inst. mar. Sci. Univ. Tex. 4: 201-227

Marsh, G. A. (1962). Studies in the ecology of the coquina clam, Donax variabilis. M. A. thesis, Univ. of North Carolina, Chapel Hill

Matta, J. F. (1977). Beach fauna study of the Coastal Engineering Research Center Field Research Facility. Duck, North Carolina. U.S. Army Corps of Engineers, Coastal Engineering Research Center, Misc. Rep. (MR-77-6): 1-102

McLachlan, A., Wooldridge, T., van der Horst, G. (1979). Tidal movements of the macrofauna on an exposed sandy beach in South Africa. J. Zool., Lond. 188: 433-442 
Mori, S. (1938). Donax semigranosis Dkr. and the experimental analysis of its behavior at the flood tide. Dobutsugaku Zasshi 50: 1-12

Mori, S. (1950). Characteristic tidal rhythmic migration of a mussel, Donax semigranosis Dkr. and the experimental analysis of its behavior. Dobutsugaku Zasshi 59: 88-89

Morrison, J. P. E. (1971). Western Atlantic Donax. Proc. Biol Soc., Wash. 83: 545-568

Pearse, A. S., Humm, H. T., Wharton, G. W. (1942). Ecology of sand beaches at Beaufort, N.C. Ecol. Monogr. 12: 135-190

Reilly, F. J., Jr., Bellis, V J. (1978). A study of the ecological impact of beach nourishment with dredged materials on the intertidal zone. East Carolina Univ. Institute for Coastal and Marine Resources, Tech. Rep. 4: 1-107

Trueman, E. R. (1971). The control of burrowing and the migratory behaviour of Donax denticulatus (Bivalvia: Tellinacea). J. Zool., Lond. 165: 453-469

Turner, H. J., Belding, D. L. (1957). The tidal migrations of Donax variabilis Say. Limnol. Oceanogr. 2: 102-124

Wade, B. A. (1967). Studies on the biology of the West Indian beach clam, Donax denticulatus 1 . Ecology. Bull. mar. Sci. 17: $149-174$

This paper was presented by Professor M. R. Carriker; it was accepted for printing on October 21,1981 